\title{
A INFÂNCIA DO CONSUMO E A EXPROPRIAÇÃO DO BRINCAR CRIATIVO
}

\author{
Daniella Caroline R. Ribeiro Ferreira (Pedagogia - UEL)
}

Profa. Dra. Marta Regina Furlan de Oliveira (orientador)

\section{RESUMO}

Este texto tem o objetivo de analisar a infância do consumo na sociedade contemporânea atrelado ao brincar tecnológico de crianças pequenas, tecendo um olhar crítico sobre as mudanças relacionadas a cultura lúdica do consumo e seus impactos nas formas de brincar e interagir de crianças, bem como o próprio processo de expropriação do brincar criativo e inventivo. O estudo é fruto das reflexões relacionadas ao Projeto de Pesquisa - "Indústria Cultural, Educação e Trabalho Docente na Primeira Infância: da semiformação à emancipação humana" da Universidade Estadual de Londrina e, ainda, das atividades de Iniciação Científica - UEL. A metodologia é estudo bibliográfico à luz dos fundamentos da teoria crítica em T. Adorno e M. Horkheimer (1985), H. Marcuse (1973) entre outros. A discussão centra-se no universo lúdico atual e o significado do brinquedo para as crianças desta sociedade que, muitas vezes, se restringe a propriedade do brinquedo, mas sem brincadeira. Como resultados, acreditase que o conceito de brincar e brincadeiras precisa ser ressignificado com olhares pedagógicos para o brincar criativo e inventivo de crianças.

Palavras-Chave: Infância. Consumo. Brincar industrializado.

\section{INTRODUÇÃO}

Este texto objetiva analisar as mudanças na cultura lúdica considerando a influência da indústria cultural, consumo na infância contemporânea e nas suas formas de brincar. Ainda, visa identificar o universo lúdico das crianças e suas brincadeiras, analisando o significado do brinquedo à luz da lógica de mercado e do consumo. Para tanto, o questionamento é o seguinte: Como tem se constituída a infância do consumo na sociedade contemporânea e quais as implicações para o brincar infantil?

Percebe-se, contudo, que as brincadeiras ditas tradicionais como, bolinhas de gude, pião, cavalo de pau, peteca, carrinho de rolimã, boneca de milho, pular corda, pega-pega, esconde-esconde, bonecas de pano entre outras, não são mais frequentes na sociedade contemporânea, visto que a organização desta sociedade e com o surgimento das tecnologias, estes brinquedos saíram de "moda". Hoje os vídeo games, a TV, computador, ou seja, os brinquedos espetaculosos da indústria cultural ocupam o espaço das atividades consideradas sadias, promovendo diversas consequências negativas na criança e na infância. (VAROTTO; SILVA, 2004, p. 170-171).

Contudo, a atividade lúdica em sua expressão máxima da qualidade humana, prepara a criança para a vida e para o mundo. Com esta a criança consegue assimilar a cultura do meio em que vive, integrando-se nele, adaptando-se a situações de vivencias em grupo, aprendendo a lidar com os sentimentos de reconhecer que ela é um sujeito social em que constitui sua individualidade a partir das relações. 


\section{SEMINÁRIO DE PESQUISA EM CIÊNCIAS HUMANAS - SEPECH \\ Humanidades, Estado e desafios didático-científicos \\ Londrina, 27 a 29 de julho de 2016}

Ao contrário disso e, considerando o sistema em que estamos inseridos, a sociedade do espetáculo tem a sua forma de controle das pessoas e no caso da criança e os brinquedos, percebemos que há uma ênfase sem medida no consumo do brinquedo e, que muitas vezes não permite a experiência criativa do brincar. É um sistema que mobiliza para viver, sentir, atuar conforme as necessidades do mercado do brinquedo, sendo estas o consumo desenfreado tanto por crianças e adultos.

Diante disso, a escola infantil e o professor tem um papel fundamental como mediador nas brincadeiras, direcionado situações lúdicas de aprendizagem e estruturando as brincadeiras para além da aquisição do brinquedo. Para isso, há a necessidade de construir um ambiente propício, com objetos lúdicos adequados e o tempo necessário, para que as crianças se organizem e desenvolvam as atividades lúdicas e interativas, uma vez que "a criança nos desafia porque ela tem uma lógica que é toda sua, porque ela encontra maneiras peculiares e muito originais de se expressar, porque ela é capaz através do brinquedo, do sonho e da fantasia de viver num mundo que é apenas seu" (CRAIDY, 2001 p. 6).

\section{REFLEXÕES SOBRE A CRIANÇA E O BRINCAR TECNOLÓGICO}

Sabemos que a concepção de infância é uma construção histórica e social. Nesse sentido, percebemos que atualmente as crianças são as principais influenciadas pela indústria de consumo e de marketing, modificando, desse modo sua infância e sua forma de brincar e interagir. No contexto social atual, o que se propaga é uma concepção de infância do consumo com seus artefatos lúdicos e industrializados.

Oliveira e Paschoal afirmam que:

Sob a égide contemporânea, vemos visivelmente se constituir um mundo infantil cada vez mais enredado pelo consumo, quando as marcas e os produtos determinam quem está 'por dentro' e quem está 'por fora', quem será alguma coisa e quem não será, quem terá amigos e quem não os terá. Em um mundo assim regulado, temos o desafio de indicar possíveis caminhos de resistência ao que está posto, indicando pela reflexão um olhar mais crítico sobre a Indústria Cultural, a infância do consumo e o brincar industrializado (OLIVEIRA, PASCHOAL,2015, p.06).

Assim, a inserção concreta das crianças e seus papéis variam com as formas de organização da sociedade. As empresas e a própria indústria cultural têm investido grandemente em brinquedos tecnológicos com a finalidade de influenciar as crianças a comprar cada vez mais, principalmente pelo desejo do objeto, da mercadoria.

Nesse cenário lúdico tecnológico, a criança se vê cercada de fetiches e clichês lúdicos que a seduzem cotidianamente para o brinquedo, para a marca e para as animações lúdicas. Assim, enquanto a mídia e a indústria cultural de brinquedos tecnológicos influenciam a criança de todas as maneiras, infelizmente presenciamos a ausência de um brincar criativo e lúdico conforme a acepção da palavra, provocando o isolamento infantil e a dependência da criança frente ao objeto-brinquedo.

A infância é refém do consumo e da mercadoria lúdica, expropriando do brincar o verdadeiro significado lúdico na brincadeira. No entanto, vale pontuar que ninguém 


\section{SEMINÁRIO DE PESQUISA EM CIÊNCIAS HUMANAS - SEPECH \\ Humanidades, Estado e desafios didático-científicos \\ Londrina, 27 a 29 de julho de 2016}

nasce consumista, as pessoas se apropriam do consumo, através das relações sociais e de comunicação, uma vez que essa nova configuração social e cultural influencia definidamente as pessoas, no caso a criança pela mediação do adulto, sendo impactadas pelas mídias e cultura de massa a consumir cada vez mais.

Dessa forma, há a presença de adultos e crianças vulneráveis ao consumo, sendo adaptados a busca incansável pelo "ter" em detrimento do "ser", onde são objetos de bombardeio das mídias nos dias atuais. As empresas deste ramo levam a sério o seu trabalho de influenciá-los a consumir o que lhe é proposto. Conforme Susan Linn (2006),

Crianças em idade pré-escolar, por exemplo, têm dificuldade em diferenciar comercias de programas normais de televisão. As crianças um pouco mais velhas sabem fazer tal distinção, mas pensam concretamente e tendem assim a acreditar no que veem num comercial de quinze segundos sobre bolachas ou brinquedos. (LINN, 2006. p.22)

As crianças não sabem distinguir a diferença entre consumismo e consumo, resultando num consumismo desenfreado e desnecessário, evidenciando em um ciclo vicioso. Nesse sentido, as pessoas são "ao mesmo tempo consumidoras e mercadorias" (MARIANGELA, MARISA 2010). As empresas de marketing usam da propaganda para influenciar as crianças de idade pré-escolar, pois aproveitam que é difícil a associação da intenção que ocorre por trás das propagandas televisivas, causando o desejo por aquilo que está vendo sobre o seu programa favorito, isso por ele conter as mesmas vozes, personagens, etc. Assim, "as crianças não conseguem realmente entender o conceito de intenção persuasiva segundo o qual cada detalhe de uma propagando foi escolhido para tornar o produto mais atraente e para convencer as pessoas a comprá-lo" (LINN, 2006. p.22).

Os pequenos são alvos extremamente importantes para as empresas, não apenas porque escolhem o que seus pais compram, mas também porque são impactados desde crianças a comprar, adquirindo hábitos consumistas e sendo fiéis a diversas marcas que são impostas em sua vida. Segundo Charaudeau (1996), a comunicação publicitária não tem autoridade para ordenar ao consumidor que compre determinado produto, no entanto, tem a função de informar sobre um determinado bem de consumo persuadindo, seduzindo e incentivando os consumidores de várias idades a adquirir o que lhes foi anunciado.

Grande parte das crianças assistem televisão sozinhas sem nenhum adulto para ajudá-las a compreender as mensagens subliminares de marketing. Mensagens essas que são direcionadas de maneira precisa, influenciando de forma significativa, por meio de propagandas em toda parte, seja em sua casa, na escola, nas ruas, etc. Diante disso, há evidências de que "o marketing se apropria da função de maldizer tudo o que se tornou obsoleto. Algo desusado no mercado de consumo é retrógado e precisa ser substituído por algo novo." (BAUMAN, 2008, p. 31).

Com o aumento e a expansão dos meios de comunicação, passaram a ser um fator de grande influência no mercado. A mídia lança rótulos e modas, onde seduzem as pessoas a comprar o que lhe é oferecido, simplesmente para ser aceito na sociedade, contendo um conceito falso de felicidade. A cultura do consumo molda o campo social, trazendo para as crianças uma experiência precoce, despertando desejos e trazendo atitudes centradas no consumo. 


\section{SEMINÁRIO DE PESQUISA EM CIÊNCIAS HUMANAS - SEPECH \\ Humanidades, Estado e desafios didático-científicos \\ Londrina, 27 a 29 de julho de 2016}

É importante salientar também sobre o padrão de beleza estabelecido pela cultura de massa através da mídia, este padrão que condiciona e aliena pessoas em um mundo onde tudo parece perfeito e feliz. A ditadura da moda é apresentada através dos meios de comunicação, as crianças são seduzidas pelo modismo e são condicionadas a gostarem das músicas, roupas, brinquedos, etc. Desta fabulosa fábrica, interferindo em suas personalidades, que se modificam conforme a "sensação do momento" da indústria cultural. Sentem-se na obrigação de pertencer a esta sociedade padronizada cultivando a necessidade de aceitação, como se não houvesse outro caminho. Adorno já dizia desde sua época que a transformação que a Indústria Cultural faz na personalidade das pessoas é o poder de controlar a sociedade a ponto de perderem suas legitimidades.

A indústria cultural abusa na sua consideração para com as massas a fim de duplicar, consolidar e reforçar sua mentalidade pressuposta como imutável. Tudo que poderia servir para transformar esta mentalidade é por ela excluído (ADORNO, 1963, p.).

Desta maneira, a mídia faz parte do cotidiano da criança, uma vez que ela passa a reproduzir muito do que vê e ouve no contexto social. Sendo, portanto, influenciadas pelos meios de comunicação de massa, que não faz distinção de pessoas, divulgando seus produtos e estimulando sejam em adultos e/ou crianças, a adaptação e o conformismo frente ao consumo e a mercadoria. Adorno e Horkheimer (1985 apud OLIVEIRA e PASCHOAL, 2015 p.) afirmam que o pensamento se vê privado "[...] não só do uso afirmativo da linguagem conceitual científica e cotidiana, mas igualmente da linguagem da oposição" Nesse sentido, as massas acabam por absorver submissamente as verdades da ciência positiva.

Há a certeza de que as crianças têm acesso a muitas informações e conforme relata Bucht (2002, p. 19) "(...) as informações fluem de maneira cada vez mais livres e com vínculos cada vez mais frouxos em tempo e lugar." No entanto, a criança precisa de um adulto que faça a mediação das informações, orientando-as para que desenvolva o pensamento crítico frente a tantas seduções e fetiches tecnológicos.

A mídia eletrônica continua a propagar-se, o aumento da violência gráfica no cinema, televisão e computadores, só foi possível porque a tecnologia nos permite fazer essas invenções. A mídia, nesse sentido, influencia o campo da ludicidade e diversão pela mercadoria, criando seus próprios valores e identidades frente ao consumo.

Não há fórmula pronta para o que seja um "bom" programa ou conteúdo de mídia. As crianças são ativas e curiosas, e elas se orientam no ambiente de maneira a construir significados. Elas querem aprender se divertir, construir relações sociais e criar sua própria identidade também no meio da mídia. (BUCH, 2002, p.69)

A indústria do consumo traz a ilusão de comprar diversas coisas sem nem ter a necessidade de possui-las. O brinquedo é fabricado para influenciar a sociedade e atender a todos, as empresas que os criam, pensam em primeiro momento, fazer as crianças acreditarem que elas realmente precisam daquele brinquedo, que ele irá te trazer felicidade e a deixará muito bem resolvida socialmente e individualmente. Muitos desses brinquedos embora tenham suas vantagens, há algo neles que infelizmente não podemos controlar como é o caso da expropriação criativa e inventiva de crianças pequenas. 


\section{SEMINÁRIO DE PESQUISA EM CIÊNCIAS HUMANAS - SEPECH \\ Humanidades, Estado e desafios didático-científicos \\ Londrina, 27 a 29 de julho de 2016}

A brincadeira, nessa concepção, frente ao consumo, possibilita e estimula o brincar solitário, ou seja, a criança se vê frente à máquina e sem estabelecer relações e vínculos afetivos com outras crianças. São raras as situações cotidianas de brincadeiras coletivas, já que cada criança e até mesmo adulto, se confinam em seus "mundos" próprios, com suas leituras e ações individuais.

Nota-se que as brincadeiras de antigamente, as brincadeiras tradicionais como: pião, peteca, boneca de materiais reciclados, pular corda, pular amarelinha, brincar de esconde-esconde, pega-pega, não são mais comuns nos dias de hoje na sociedade em que vivemos, pois com o surgimento da tecnologia, os brinquedos confeccionados a mão, deixam de existir, dando espaço para os videogames, TV, tablete, computadores, etc. Os brinquedos da indústria de consumo substituíram os brinquedos considerados importantes para a infância da criança, trazendo assim consequências negativas para o seu desenvolvimento.

Com o avanço da Revolução Industrial e das recentes tecnologias, os brinquedos tradicionais foram substituídos por brinquedos de plástico, os quais permitem entrar no mundo dos adultos. Aparecem aviões, trens, bonecas na moda, com roupas e acessórios, carros de combate, munições, brinquedos rápidos e cheios de novas tecnologias: sons, ritmos, ruídos, com destrezas e piruetas.

A tese de Postman (1999) estuda o desaparecimento da infância seguindo o pressuposto de que não existem mais diferenças entre a fase adulta e a infância. Realmente, a infância de hoje não esta nada parecida com a do passado, porém vale a pena salientar que as formas de brincar e seus brinquedos são outros, os tipos de brincadeiras, a forma como usa o espaço e a imaginação estão completamente diferentes.

Tomando como referência Levin (2007), os brinquedos dessa nova geração de infância são extremamente marcados por serem sem ação, não leva a criança a exploralo, causando assim uma criança sem corpo, pois o corpo está em outro lugar, ou na tela ou no game. Esses brinquedos são reflexos de um sistema de produção capitalista que manipula a sociedade, onde o que importa é o "ter" e não o ser de cada individuo.

No meio infantil, com as novas tecnologias, que poderá ser usada através de computadores, celulares, jogos eletrônicos, tablets e etc, alterou as formas de brincar e de seu espaço. As mídias e as tecnologias transformaram as brincadeiras das crianças e, concomitantemente, alterou a forma com que elas se interagem umas com as outras.

Alguns dos fragmentos que compõem o contexto da infância contemporânea são: crianças pequenas com agenda lotada; a televisão que se transforma em babá; pais ausentes; carrinho transformado em objeto; erotização da infância; sexualidade; publicidade; cultura do consumo; criança que manda nos pais (PEREIRA; JOBIM E SOUZA, 1998, p. 37).

Postman (1999) explica que na atualidade, as brincadeiras infantis foram "adultizadas", de modo que um jogo infantil se tornou profissionalização e motivo de preocupação dos adultos. Não se observa mais com tanta intensidade marcas que lembrem um mundo infantil separado do mundo dos adultos (MÉLO, IVASHITA, RODRIGUES 2009, p. 315)

É importante salientar a necessidade de se preocupar com o que as crianças brincam, pois há uma necessidade de brincar entre elas, que deveria ser um brincar lúdico, com atividades interativas, trazendo a criatividade e a imaginação, não apenas um brinquedo pronto, que expropria essa potencialidade de ser desenvolvida com as 


\section{SEMINÁRIO DE PESQUISA EM CIÊNCIAS HUMANAS - SEPECH \\ Humanidades, Estado e desafios didático-científicos \\ Londrina, 27 a 29 de julho de 2016}

crianças. Através do brinquedo a criança consegue viver um mundo que é só seu, aguçar a imaginação para brincar. De acordo com Borba (2006, p.38):

É importante enfatizar que o modo próprio de comunicar do brincar não se refere a um pensamento ilógico, mas a um discurso organizado com lógica e características próprias, o qual permite que as crianças transponham espaços e tempos e transitem entre os planos da imaginação e da fantasia explorando suas contradições e possibilidades. Assim, o plano informal das brincadeiras possibilita a construção e a ampliação de competências e conhecimentos nos planos da cognição e das interações sociais, o que certamente tem consequências na aquisição de conhecimentos nos planos da aprendizagem formal (BORBA, 2006, p.38).

Vimos que a atividade lúdica prepara a criança para o mundo, com base nisto, os ambientes escolares exercem um papel extremamente importante na vida das crianças, guiando sempre suas intervenções na ludicidade, e trazendo brincadeiras para além da posse do brinquedo, para despertar a autonomia e imaginação dos alunos.

A escola tem como papel, compreender as diferenças e notar que os alunos e seus brinquedos mudaram, com isto surge à necessidade da escola em manter uma relação de compreensão e reflexão, de modo que a escola não se acomode, a escola deve ajuda-los a lidar com o novo, mas também lhes apresentar os brinquedos de antigamente, possibilitando um vinculo entre passado e presente, Para Corazza (2005):

$\mathrm{Ou}$ aprendemos as lições deste tempo e fazemos os diferentes e suas culturas entrarem, efetivamente, em nossos currículos e práticas pedagógicas, ou vamos acabar cedendo nosso lugar de educadores críticos para os a - críticos funk, futebol, ruas, gangues, drogas, Internet, prostituição infantil, filmes da Disney, tele turma, tele namoro, teles sexo. Ou a diferença se torna, de uma vez por todas, a principal argila de nosso trabalho pedagógico e curricular, ou seremos educadores perdidos, à deriva, fora de nosso tempo. E o que é mais grave: não estaremos educando nossos alunos para um porvir plural e criativo, em que a educação faça diferença. (2005, p. 21).

A escola, nesse sentido, precisa ser um local onde a criança seja o principal sujeito do processo educativo, uma relação ambígua entre educador e educando, onde ambos procuram o aperfeiçoamento, sobre esse processo Corazza afirma que:

Nos dias de hoje os movimentos sociais e a teorização cultural não podem mais ser os mesmos, o currículo e a Pedagogia não podem agir e nem pensar como antes, os professores e alunos não podem educar nem serem educados como até então. Eles saem da camisa-de-força da categoria social para explodir os seus entendimentos e práticas em mil pequenos marcadores sociais. (CORAZZA, 2005, p.18).

Então, o que deverá ser feito? Proibir as crianças de brincarem com esses tipos de brinquedos? Parar de assistir televisão? Sobre essa problemática, Gonçalves pontua que "a questão em si não é proibição de programas televisivos, brinquedos, livros ou outros objetos explorados pela mídia, o que urge é a necessidade de esclarecimento, de 


\section{SEMINÁRIO DE PESQUISA EM CIÊNCIAS HUMANAS - SEPECH \\ Humanidades, Estado e desafios didático-científicos \\ Londrina, 27 a 29 de julho de 2016}

uma (re) leitura desses produtos, impossibilitando a infância de ser massacrada." (2005, p. 16). Portanto, o consumismo e seus impactos devem ser conversado tanto na escola como no ambiente familiar, é importante alertar, dialogar sobre o que está sendo produzido pela mídia e seus meios de comunicação e tecnologia avançada.

\section{O BRINCAR PARA ALÉM DA MERCADORIA: TECENDO ALGUMAS CONSIDERAÇÕES FINAIS}

As escolas de hoje, deverão estar em constante prática de repensar. Cabe a ela apropriar-se dos brinquedos atuais, buscando novas formas de conhecimento, já que é de extrema importância a escola democratizar o acesso ao conhecimento, disponibilizando as tecnologias de comunicação e informação, valorizando assim a interdisciplinaridade. Esta escola mediará para formar um individuo que reflita suas ações de maneira crítica, condições essas que são fundamentais para a vida nos dias atuais.

Conforme o autor Craidy (2001) nos diz, "a criança nos desafia porque ela tem uma lógica que é toda sua, porque ela encontra maneiras peculiares e muito originais de se expressar, porque ela é capaz através do brinquedo, do sonho e da fantasia de viver num mundo que é apenas seu" (CRAIDY, 2001 p. 6). Nesse prisma, considera-se relevante ressignificar o brincar enquanto atividade humana criadora, na qual imaginação, fantasia e realidade interagem na produção de novas possibilidades de interpretação, de expressão e de ação pelas crianças, assim como de novas formas de construir relações sociais com outros sujeitos, crianças e adultos.

Vygotsky compreende que, se por um lado a criança de fato reproduz e representa o mundo por meio das situações criadas nas atividades de brincadeiras, por outro lado tal reprodução não se faz passivamente, mas sim mediante a um processo ativo de reinterpretação do mundo, que abre lugar para a invenção e a produção de novos significados, saberes e práticas. Como ressalta Machado:

\footnotetext{
Brincar é também um grande canal para o aprendizado, senão o único canal para verdadeiros processos cognitivos. Para aprender precisamos adquirir certo distanciamento de nós mesmos, e é isso o que a criança pratica desde as primeiras brincadeiras transicionais, distanciando-se da mãe. Através do filtro do distanciamento podem surgir novas maneiras de pensar e de aprender sobre o mundo. Ao brincar, a criança pensa, reflete e organiza-se internamente para aprender aquilo que ela quer, precisa, necessita, está no seu momento de aprender; isso pode não ter a ver com o que o pai, o professor ou o fabricante de brinquedos propõem que ela aprenda". (MACHADO, 2003, p.37)
}

O brincar na vida da criança é importante, pois é o único meio de desenvolver o aprendizado cognitivo da criança, as brincadeiras proporcionam para a criança a oportunidade de pensar, refletir, criar, recriar, imaginar, fazer um mundo que é só dela, e o correto é que isto não seja influenciado por meios que não irão ajudar nesse processo. A criança deverá obter todo o apoio para brinquedos e brincadeiras que a estimule a se desenvolver não apenas a posse do brinquedo.

Assim, conforme Huizinga (1996), o lúdico deve ser considerado uma das ações primordiais da vida, já que os jogos e brincadeiras tem ocupado historicamente um 


\section{SEMINÁRIO DE PESQUISA EM CIÊNCIAS HUMANAS - SEPECH \\ Humanidades, Estado e desafios didático-científicos \\ Londrina, 27 a 29 de julho de 2016}

lugar muito importante nas mais diversas culturas. Segundo o autor na sociedade antiga, o trabalho não tinha o valor que tem e não ocupava quase o dia todo do ser humano, os jogos e brincadeiras, eram um dos principais meios da sociedade para melhorar a relação entre eles e se tornarem unidos.

O jogo e o lúdico não são apenas "loucura", e podem estar muito bem situados entre as atividades regradas e corretas que participam da sensatez. Na língua alemã, como no grego, as palavras podem associar múltiplos significados. Spass é divertimento, com prazer. Não é um divertimento qualquer. Spass deve conter satisfação autêntica. Witz é mais do humor, do nível do entendimento que faz rir, que provoca o humor (HUIZINGA, 1996. p. 77).

O lúdico através dos jogos leva a criança ao desenvolvimento do prazer e da fantasia e imaginação, independentemente do objeto/mercadoria. Nesse sentido, acredita-se que:

O elemento lúdico vai gradualmente passando para segundo plano, sendo sua maior parte absorvida pela esfera do sagrado. $\mathrm{O}$ restante cristaliza-se sob a forma de saber: folclore, poesia, filosofia, e as diversas formas da vida jurídica e política. Fica assim completamente oculto por detrás dos fenômenos culturais o elemento lúdico original (HUIZINGA,1996. p. 54).

No campo da educação, devemos perceber e analisar todas essas dificuldades que as crianças têm enfrentado nos dias de hoje com o atual bombardeio da indústria cultural. A escola tem um papel fundamental na superação desse meio consumista em que estamos inseridos, onde o educador poderá ajudar as crianças, apresentando-as um meio de consciência e reflexão, para que não se perca a sua infância e seu desenvolvimento através do brincar. É nosso papel ajudar as crianças a conviver com as tecnologias, mas devemos saber fazer o uso dessas de maneira que não às prejudique.

\section{REFERÊNCIAS}

BAUMAN, Z, 1925. Vida para consumo: a transformação das pessoas em mercadoria/ Zygmunt Bauman; tradução Carlos Alberto Medeiros. Rio de Janeiro:Zahar, 2008.

BORBA, A. M. O brincar como um modo de ser e estar no mundo. In: Orientações para a inclusão da criança de seis anos de idade. Brasília: Ministério da Educação, 2007.

BUCHT, C. Perspectivas sobre a criança e a mídia. Brasília: UNESCO,2002.

CORAZZA, S. M. Uma vida de professora. Ijuí:Unijuí, 2005.

CRAIDY. C. Educação infantil: pra que te quero? Porto Alegre:Art. Med. 2001. 


\section{SEMINÁRIO DE PESQUISA EM CIÊNCIAS HUMANAS - SEPECH \\ Humanidades, Estado e desafios didático-científicos \\ Londrina, 27 a 29 de julho de 2016}

CHARAUDEAU, P. Para uma nova analise do discurso. In: CARNEIRO, Agostinho Dias (org). O discurso da Mídia. Rio de Janeiro: Oficina do Autor, 1996.

GONÇALVES, A.do .C.G. Contextualização da Infância no Espaço Urbano: os possíveis efeitos da globalização. Momento, Rio Grande,2004/2005.

HORKHEIMER, M.; ADORNO, T. W. A Dialética do esclarecimento: fragmentos filosóficos. Rio de Janeiro: Jorge Zahar, 1985.

HUIZINGA, J. Homo ludens: o jogo como elemento da cultura. 4. ed. São Paulo: Perspectiva, 1996.

LINN, S. Crianças do Consumo: A Infância Roubada. São Paulo: Instituto Alana, 2006. $322 \mathrm{p}$.

MACHADO, M. M. O brinquedo-sucata e a criança. Edições Loyola, 2003.

MARCUSE, Herbert. A ideologia da sociedade industrial. Rio de Janeiro: Zahar, 1973.

MELO, C. S, IVASHITA. S.B, RODRIGUES: POSTMAN, Neil. O Desaparecimento da Infância. Tradução: Suzana Menescal de A. Carvalho e José Laurenio de Melo. Rio de Janeiro: Grafhia Editorial, 2009. Revista HISTEDBR On-line, Campinas, n.35, p. 311-316, set.2009 - ISSN: 1676-2584.

OLIVEIRA, M. R. F. de.; PASCHOAL, J. D . A infância do consumo e a expropriação do pensamento criativo e inventivo. Curitiba 2015.

PEREIRA, R. M. R.; JOBIM E SOUZA, S. Infância, conhecimento e contemporaneidade. In: KRAMER, S.; LEITE, M. I. Infância e produção cultural. Campinas: Papirus, 1998. p. 25-42.

POSTMAN, Neil. O desaparecimento da infância. Rio de Janeiro: Graphia, 1999.

VAROTTO, A, M; SILVA, M. R. da. Brinquedo e indústria cultural: Sentidos e significados atribuídos pelas crianças. Motrivivência, Santa Catarina, n. 23, p. 169190, dez. 2004. 